\title{
Femina Abdul Salam and Anantharaman Narayanan* Leached compounds from the extracts of pomegranate peel, green coconut shell, and karuvelam wood for the removal of hexavalent chromium
}

https://doi.org/10.1515/gps-2018-0085

Received April 23, 2018; accepted August 2, 2018; previously published online September 27, 2018

\begin{abstract}
During biosorption, the biosorbent releases many organic compounds to the medium. In the present study, extracts of pomegranate peel (PP), green coconut shell (GCS), and karuvelam wood (KW) were prepared at three different conditions, namely $12 \mathrm{~h}, 3 \mathrm{~h}$, and $3 \mathrm{~h}$ at $\mathrm{pH} 2$, for the removal of hexavalent chromium $[\mathrm{Cr}(\mathrm{VI})]$. The amount of organic compounds, mainly the leached organic compounds in the extract before and after treatment with $\mathrm{Cr}(\mathrm{VI})$ solution, was determined by chemical oxygen demand analysis. The total phenolic content, antioxidant activity, and total flavonoid content were used to estimate the chromium reduction potential of the extracts. The PP extract is the richest in all the three factors, followed by GCS and KW. The disappearance rate of $\mathrm{Cr}(\mathrm{VI})$ in the presence of PP extract reached $99.63 \%$ for the $50 \mathrm{mg} / \mathrm{l}$ concentration within $3 \mathrm{~min}$, while it was $12 \%$ and $10 \%$ for GCS and KW, respectively, for the same concentration and time. Reaction mechanisms were formulated with the help of Fourier transform infrared spectroscopy to confirm the role of leached compounds from natural materials for the removal of heavy metal.
\end{abstract}

Keywords: antioxidant activity; biosorption; chromium reduction potential; total flavonoid content; total phenolic content.

\section{Abbreviations}

$\begin{array}{ll}\text { COD } & \text { chemical oxygen demand } \\ \text { Cr(III) } & \text { trivalent chromium } \\ \text { Cr(VI) } & \text { hexavalent chromium } \\ \text { DDW } & \text { double-distilled water } \\ \text { DPPH } & \text { 2,2-diphenyl-1-picrylhydrazyl } \\ \text { GAE } & \text { gallic acid equivalent }\end{array}$

*Corresponding author: Anantharaman Narayanan, Department of Chemical Engineering, National Institute of Technology Tiruchirappalli, Tiruchirappalli 620 015, Tamil Nadu, India, e-mail: naraman@nitt.edu

Femina Abdul Salam: Department of Chemical Engineering, National Institute of Technology Tiruchirappalli, Tiruchirappalli 620 015, Tamil Nadu, India

\author{
GCS \\ KW \\ PP \\ TPC \\ TFC \\ green coconut shell \\ karuvelam wood \\ pomegranate peel \\ total phenolic content \\ total flavonoid content
}

\section{Introduction}

The emission of toxic heavy metals to the biosphere increases due to rapid industrialization and urbanization, producing adverse effects on the ecosystem [1]. Pollution caused by heavy metals like chromium, arsenic, lead, etc., is one of the most significant issues faced by environmentalists [2]. Chromium is a widely used heavy metal in tanneries, electrochemical industries, and other chemical industries. In nature, chromium mainly exists in two oxidation states: hexavalent chromium $[\mathrm{Cr}(\mathrm{VI})]$ and trivalent chromium [Cr(III)] [3]. $\mathrm{Cr}(\mathrm{VI})$ causes many health issues, such as breathing problems, allergy, cancer, etc. [3, 4]. As per the guidelines of the World Health Organization and the Central Pollution Control Board of India, the total chromium content of drinking water is restricted to $0.05 \mathrm{mg} / \mathrm{l}$ [5-8]. Thus, the removal of $\mathrm{Cr}(\mathrm{VI})$ is highly essential to overcome the toxic effects.

With respect to the variations in $\mathrm{pH}$ of the medium, the ionic forms of chromium also differ. Cr(III) on hydrolysis results in compounds like neutral species $\mathrm{Cr}(\mathrm{OH})_{3}{ }^{0}$, mononuclear species $\mathrm{Cr}(\mathrm{OH})_{2}^{+}, \mathrm{CrOH}^{2+}, \mathrm{Cr}(\mathrm{OH})_{4}^{-}$, polynuclear species $\mathrm{Cr}_{3}(\mathrm{OH})_{4}^{5+}$, and $\mathrm{Cr}_{2}(\mathrm{OH})_{2}$. Hydrolysis of $\mathrm{Cr}(\mathrm{VI})$ at low $\mathrm{pH}$ and higher concentration produces $\mathrm{Cr}_{2} \mathrm{O}_{7}^{2-}$ and $\mathrm{CrO}_{4}^{2-}$ at $\mathrm{pH}>6.5$ [3]. The redox potential-pH and speciation diagrams show that $\mathrm{Cr}(\mathrm{VI})$ exists primarily as a salt of chromic acid $\left(\mathrm{H}_{2} \mathrm{CrO}_{4}\right)$ at $\mathrm{pH}<1$, hydrogen chromate ion $\left(\mathrm{HCrO}_{4}^{-}\right)$at $\mathrm{pH}$ between 1 and 6 , and chromate ion $\left(\mathrm{CrO}_{4}^{2-}\right)$ at $\mathrm{pH}>6$ [4].

In recent times, the research community is searching for cheap and eco-friendly technology for heavy metal removal, and it has been found that biosorption is a better option. Biosorption is a sorption process where naturally occurring living and non-living things act as a biosorbent. During biosorption, many colored organic compounds are released into the medium. The literature reports that these released compounds have significant roles in the removal of heavy metals. The amount of released pigments during biosorption 
can be quantified in terms of chemical oxygen demand (COD) representing the $\mathrm{Cr}(\mathrm{VI})$ reduction potential $[9,10]$. Various plant parts are natural materials releasing compounds such as flavonoids, polyphenols, terpenoids, aldehydes, ketones, carboxylic acids, ether groups, and tannins, which have the ability to chelate metal catalysts [11-13].

Aquatic weeds [10], palm flower [9], rice husk [14], lemon shell [15], mangosteen peel [16], and many other biomaterials have been experimented on for the removal of chromium. In the present study, the $\mathrm{Cr}(\mathrm{VI})$ removal efficiency of the released compounds from pomegranate peel (PP), green coconut shell (GCS), and karuvelam wood (KW) were estimated based on COD, total phenolic content (TPC), antioxidant activity, and total flavonoid content (TFC). A review of the literature indicates that chromium removal based on the aforementioned properties has not yet been reported previously.

\section{Materials and methods}

\subsection{Plant materials}

The three biomaterials chosen for the preparation of extracts were peel of Punica granatum L. (pomegranate), shell of Cocos nucifera (coconut), and wood of Prosopis juliflora (karuvelam), which are all cheaply and abundantly available in the southern part of India. The main selection criterion for their choice was effective waste utilization. Raw materials for extract preparation were collected from the National Institute of Technology, Tiruchirappalli Campus. The biomaterials were initially washed with tap water to remove dust and dirt, and then washed three times with double-distilled water (DDW). Subsequently, they were dried under the sun for 3 days and in an oven for $24 \mathrm{~h}$ at $318 \mathrm{~K}$. All the dried materials were powdered and sieved, and a particle size of $125 \mu \mathrm{m}$ was chosen.

\subsection{Chemicals}

Potassium dichromate, sodium nitrite, sodium nitrate, sodium hydroxide, aluminum chloride, ferric chloride, 1,5-diphenylcarbazide, hydrochloric acid, sulfuric acid, a sodium carbonate and COD solution A and B of Spectroquant were purchased from Merck (Mumbai, Maharashtra, India). 2,2-Diphenyl-1-picrylhydrazyl (DPPH) (Sigma Aldrich CHEMIE, GmbH, Steinheim, Germany), gallic acid, and Folin-Ciocalteu reagent were procured from Nice Chemicals, Pvt. Ltd. (Cochin, Kerala, India). All the chemicals used were of analytical grade.

\subsection{Extract preparation}

Extracts were prepared for each material (PP, GCS, and KW) at three different conditions: (i) $12 \mathrm{~h}$ soaking - soaking of material for $12 \mathrm{~h}$ in DDW for maximum extraction of water-soluble compounds from the biosorbent for maximum $\mathrm{Cr}(\mathrm{VI})$ removal, (ii) $3 \mathrm{~h}$ soaking - soaking of material in DDW for $3 \mathrm{~h}$, and (iii) $3 \mathrm{~h}$ soaking of material in DDW at a $\mathrm{pH}$ of 2 (adjusted using $\mathrm{HCl}$ ). The conditions were selected based on preliminary studies, as $\mathrm{pH} 2$ displayed better reduction of chromium for a given specified time than other $\mathrm{pH}$ values. For all the three extraction conditions and biomaterials, $1 \mathrm{~g}$ of sample was soaked in Erlenmeyer flasks containing $100 \mathrm{ml}$ DDW and placed in an orbital shaker at $150 \mathrm{rpm}$ at $303 \mathrm{~K}$. After soaking, the extract was vacuum filtered and stored at $4^{\circ} \mathrm{C}$.

\subsection{Characterization of extracts}

2.4.1 COD analysis: The amount of water-soluble compounds released during biosorption and the compounds that remained in solution after interaction with $\mathrm{Cr}(\mathrm{VI})$ solution were measured by $\mathrm{COD}$ analysis using a closed reflux method as per American Public Health Association [17].

For COD analysis, $2.2 \mathrm{ml}$ of COD solution A and $1.8 \mathrm{ml}$ of COD solution B were added to $1 \mathrm{ml}$ distilled water in sample bottles and digested at $150^{\circ} \mathrm{C}$ for $120 \mathrm{~min}$. Samples were cooled to room temperature and analyzed in Spectroquant colorimeter. The same procedure was repeated with extracts instead of distilled water. All the experiments were done in triplicate.

2.4.2 TPC: In the test to ascertain the presence of TPC as per Madaan et al. [18], $1 \mathrm{ml} \mathrm{FeCl}_{3}$ was added to $1 \mathrm{ml}$ extract. A dark blue color developed with the PP extract and a lighter blue color in the GCS and KW extracts, which indicated the presence of phenolic content. Quantitative determination of TPC before and after biosorption of $\mathrm{Cr}(\mathrm{VI})$ was determined and expressed as gallic acid equivalents (mg/g) [18]. Gallic acid stock solution was prepared by dissolving $5 \mathrm{mg}$ gallic acid in $10 \mathrm{ml}$ ethanol, and then made to $100 \mathrm{ml}$ with DDW. For preparing a calibration curve, solutions of various concentrations of gallic acid were prepared from the stock solution. Aliquots $(1 \mathrm{ml})$ of each dilution were then added with $10 \mathrm{ml}$ DDW and $1.5 \mathrm{ml}$ FolinCiocalteu reagent. The solution was mixed well and incubated for $5 \mathrm{~min}$ at room temperature. A $4 \mathrm{ml}$ volume of $20 \% \mathrm{Na}_{2} \mathrm{CO}_{3}$ (w/w) was added to each test tube, and it was made to $25 \mathrm{ml}$ with DDW. This mixture was agitated and left aside for $30 \mathrm{~min}$. The absorbance was determined at a wavelength of $765 \mathrm{~nm}$. The calibration curve was plotted using absorbance against gallic acid concentration. Gallic acid was replaced with the sample extract for finding the TPC present in the extract. TPC was then calculated from Eq. (1), as given in the literature [19]. All experiments were done in triplicate.

$$
\mathrm{TPC}=\mathrm{GAE} \times V \times \frac{D}{m}
$$

where GAE is the gallic acid equivalent ( $\mathrm{mg} / \mathrm{l}), V$ is the volume of extract (l), $D$ is dilution factor, and $m$ is the weight (g) of the plant extract.

2.4.3 Antioxidant activity: Colorimetry using DPPH was followed for the determination of antioxidant activity or percentage inhibition, as it is reported as a fast, easy, and reliable method [20]. DPPH is a stable synthetic radical that can easily accept $\mathrm{H}^{+}$ions from the phenolic compounds present in the extract by the following reaction:

$$
\mathrm{DPPH}^{\star}+\mathrm{A}-\mathrm{H} \rightarrow \mathrm{DPPH}-\mathrm{H}+\mathrm{A}^{\star} .
$$

For this, $0.02 \mathrm{~g}$ DPPH was dissolved in $50 \mathrm{ml}$ ethanol to produce a solution of a concentration of $0.4 \mathrm{mg} / \mathrm{ml}$. A volume of $5 \mathrm{ml}$ of each extract $(1 \mathrm{mg} / \mathrm{ml})$ was added to $1 \mathrm{ml} \mathrm{DPPH}$ and made to $10 \mathrm{ml}$ with 
ethanol. Absorbance was measured at $517 \mathrm{~nm}$. Antioxidant activity was calculated using Eq. (3), as given by Kalita et al. [21] and Sahu and Saxena [22]. All the experiments were done in triplicate.

$$
\text { Percentage inhibition }=\left(1-\frac{\text { Absorbance of test }}{\text { Absorbance of control }}\right) \star 100 \text {. }
$$

2.4.4 TFC: The presence of TFC in the extract was identified as described by the American Public Health Association [17] and Madaan et al. [18]. A few drops of dilute $\mathrm{NaOH}(0.1 \mathrm{M})$ was added to $1 \mathrm{ml}$ extract, which was initially yellow in color and then the color disappeared upon adding dilute $\mathrm{HCl}(0.1 \mathrm{M})$. This confirmed the presence of flavonoids. The TFC was estimated using the aluminum chloride method, and the results were expressed as quercetin equivalents [22, 23]. For plotting the calibration curve, various concentrations of standard quercetin solutions were prepared from the stock solution of $100 \mathrm{mg} / \mathrm{l}$ by serial dilution. A $1 \mathrm{ml}$ volume of the standard solution was taken in a test tube containing $4 \mathrm{ml}$ DDW, and to this $0.3 \mathrm{ml}$ of $5 \% \mathrm{NaNO}_{2}$ was added. After $5 \mathrm{~min}, 0.3 \mathrm{ml}$ of $10 \% \mathrm{Al}_{2} \mathrm{Cl}_{3}$ was added to the mixture. After $6 \mathrm{~min}, 2 \mathrm{ml}$ of $1 \mathrm{M} \mathrm{NaOH}$ was added and it was made up to $10 \mathrm{ml}$ with DDW. The procedure was repeated with the extracts instead of standard quercetin for estimating the TFC in the extract. Absorbance was measured at $475 \mathrm{~nm}$. All the experiments were done in triplicate.

2.4.5 Quantification of $\mathrm{Cr}(\mathrm{VI})$ : The 1,5-diphenyl carbazide method was used for evaluating $\mathrm{Cr}(\mathrm{VI})$. Absorbance was measured at $540 \mathrm{~nm}$ using a Shimadzu ultraviolet-visible spectrophotometer. For this analysis, a stock solution of concentration $1000 \mathrm{mg} / \mathrm{l}$ was prepared by dissolving the required quantity of potassium dichromate in DDW. $\mathrm{Cr}(\mathrm{VI})$ solution $(50 \mathrm{mg} / \mathrm{l})$ was prepared by serial dilution of the stock solution. A $100 \mathrm{ml}$ volume of each of these solutions was taken in three separate $250 \mathrm{ml}$ Erlenmeyer flasks. The $\mathrm{pH}$ of the solution was adjusted to 2 . A $10 \mathrm{ml}$ volume of each extract prepared at three different conditions ( $12 \mathrm{~h}, 3 \mathrm{~h}$, and $3 \mathrm{~h}$ at $\mathrm{pH}$ 2) was added. It was kept in the incubator shaker for $3 \mathrm{~h}$ for attaining equilibrium at $303 \mathrm{~K}$. For the kinetic study of $\mathrm{Cr}(\mathrm{VI})$ removal, samples were drawn at different time intervals. All experiments were done in triplicate.

$\mathrm{The} \mathrm{Cr}(\mathrm{VI})$ quantification was also confirmed with the total chromium results in atomic absorption spectroscopy (AAS) to account for any $\mathrm{Cr}(\mathrm{III})$ present.

2.4.6 Fourier transform infrared spectroscopy (FTIR) analysis of extracts: The FTIR spectra of the extracts prepared at different conditions were taken. Differences in peak intensity and disappearance of various peaks were observed with extracts before and after treatment with $\mathrm{Cr}(\mathrm{VI})$ solution.

\section{Results and discussion}

Performance evaluation of the extracts prepared from PP, GCS, and KW for the removal of $\mathrm{Cr}(\mathrm{VI})$ is presented on the basis of COD, TPC, TFC, and antioxidant activity. Initial investigations showed the effect of $\mathrm{pH}$ in the process along with time influencing the potential of the three extracts in the study. The extraction conditions were
$12 \mathrm{~h}, 3 \mathrm{~h}$, and $3 \mathrm{~h}$ at $\mathrm{pH} 2$ for performance assessment of all the three extracts. The contents of the natural materials (PP, GCS, and KW) were found to be responsible for the efficient removal of the metal. The main functional groups were from polyphenolic compounds, flavonoids, carboxylic acids, and other contents, which could account for the possible reaction mechanisms with $\mathrm{Cr}(\mathrm{VI})$, with FTIR analysis supporting the findings.

\subsection{COD analysis}

COD analysis was performed to quantify the organic compounds released into the medium. The presence of various types of leached compounds have been reported earlier, as polyphenols, condensed tannins, hydrolyzable tannins, and gallotannins in PP extract [13, 23, 24]; phenolic compounds in GCS [25]; and alkaloids, flavonoids, and tannins in KW [26].

The organic compounds extracted from PP, GCS, and KW were calculated in terms of COD. The higher amount of initial COD value is an indication of the amount of reducing compounds present in the extract. The COD values estimated before and after treatment of extract with $50 \mathrm{mg} / \mathrm{l} \mathrm{Cr}(\mathrm{VI})$ solution are listed in Table 1. The difference in COD values show the amount of reduction or amount of proton $\left(\mathrm{H}^{+}\right)$transferred during biosorption. In the reduction process, the PP extract had the higher initial COD values of 4580, 4620, and 5830 for the extracts obtained after $12 \mathrm{~h}, 3 \mathrm{~h}$, and $3 \mathrm{~h}$ at $\mathrm{pH} 2$, respectively, due to higher organic contents. About $90 \pm 2 \%$ COD reduction was achieved in all the three conditions by the PP extract, exhibiting the highest reduction compared with the other two extracts. The initial COD value of the GCS extract was higher than that of the KW extract; however, the reduction observed was much less in GCS than in KW. In KW, about $84-86 \%$ of COD reduction was obtained for the initial COD values of 2220 and 1850 for the extracts obtained after 12 and $3 \mathrm{~h}$ of extraction time, respectively, demonstrating lesser chromium reduction owing to a reduced amount of organics released from it. This indicates that the compounds leached from GCS were more stable as the leachate contains phenolic compounds with fewer multiple hydroxyl groups. Mathew et al. had inferred the higher reduction potential of phenolic compounds with multiple hydroxyl groups [27]. It was noticed that $3 \mathrm{~h}$ at $\mathrm{pH} 2$ is the most favorable condition for the extraction of organic compounds from raw materials. Hence, the $\mathrm{pH}$ of the solution plays a more important role than contact time for leaching organic compounds from all extracts. 
Table 1: Change in $\mathrm{COD}$ before and after adsorption of $\mathrm{Cr}(\mathrm{VI})$ from $50 \mathrm{mg} / \mathrm{l}$ solution.

\begin{tabular}{|c|c|c|c|c|c|c|c|c|c|}
\hline \multirow{2}{*}{$\begin{array}{l}\text { Condition for } \\
\text { extraction }\end{array}$} & \multicolumn{3}{|r|}{ PP } & \multicolumn{3}{|r|}{ GCS } & \multicolumn{3}{|r|}{ KW } \\
\hline & $\begin{array}{r}\text { Initial COD } \\
(\mathrm{mg} / \mathrm{l})\end{array}$ & $\begin{array}{r}\text { Final COD } \\
(\mathrm{mg} / \mathrm{l})\end{array}$ & $\begin{array}{r}\% \text { Reduction } \\
\text { of COD }\end{array}$ & $\begin{array}{r}\text { Initial COD } \\
(\mathrm{mg} / \mathrm{l})\end{array}$ & $\begin{array}{r}\text { Final COD } \\
(\mathrm{mg} / \mathrm{l})\end{array}$ & $\begin{array}{r}\% \text { Reduction } \\
\text { of COD }\end{array}$ & $\begin{array}{r}\text { Initial COD } \\
(\mathrm{mg} / \mathrm{l})\end{array}$ & $\begin{array}{r}\text { Final COD } \\
(\mathrm{mg} / \mathrm{l})\end{array}$ & $\begin{array}{r}\% \text { Reduction } \\
\text { of COD }\end{array}$ \\
\hline $12 \mathrm{~h}$ & 4580 & 390 & 91.5 & 2670 & 1770 & 33.7 & 2220 & 320 & 85.6 \\
\hline $3 \mathrm{~h}$ & 4620 & 520 & 88.7 & 2680 & 1290 & 51.9 & 1850 & 300 & 83.78 \\
\hline $3 \mathrm{~h}$ at $\mathrm{pH} 2$ & 5830 & 630 & 89.2 & 2810 & 2380 & 15.3 & 3620 & 310 & 91.4 \\
\hline
\end{tabular}

\subsection{TPC}

The color intensity during the initial experiments depicted the presence of large amounts of TPC in PP extract compared to the other two extracts. After mixing with $\mathrm{Cr}(\mathrm{VI})$ solution, the intensity of color was reduced for PP and no color change was observed in the case of GCS and KW extracts due to the complete utilization of phenolic compounds from GCS and KW. The calibration curve for gallic acid given in Figure 1 was used for calculating TPC. Table 2 gives the amount of TPC present in the extracts before and after the removal of $\mathrm{Cr}(\mathrm{VI})$ from a $50 \mathrm{mg} / \mathrm{l}$ solution. Although the initial TPC of PP extract is higher, a significant drop in TPC was seen. However,

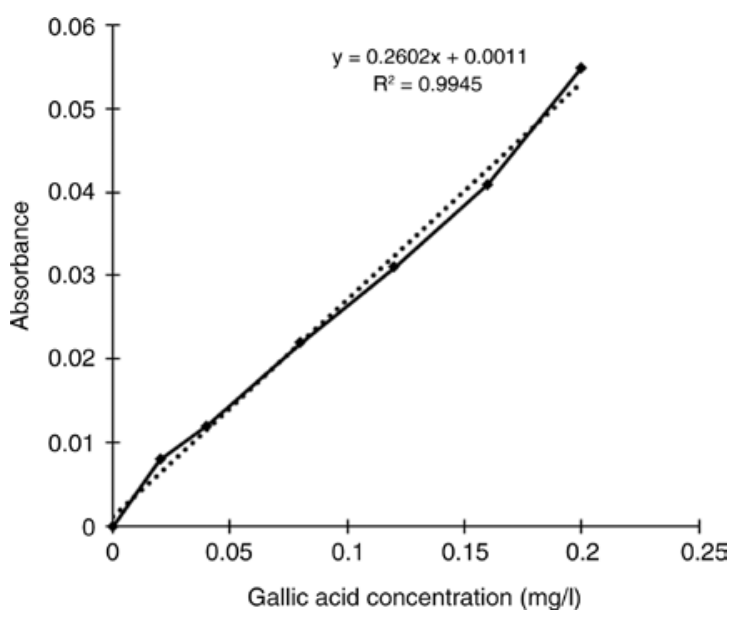

Figure 1: Calibration curve for gallic acid. with GCS and KW, the initial TPC was less, and after the removal of chromium, no TPC was observed in them for all the conditions.

\subsection{Antioxidant activity}

The antioxidant activity of plant extracts is mainly due to the presence of phenolic and polyphenolic compounds in them. This is an indirect measurement of their free radical scavenging activity, which depends on the ability of the compounds to lose hydrogen [20]. It also helps in understanding the main structure, the structure of the side chains, and the substitutions on aromatic rings [28]. The radical scavenging potential is determined by the number and position of the hydroxyl group and the methoxy group in the phenolic ring [27]. The majority of naturally occurring antioxidants are in the form of phenolic and flavonoid structures, which mostly account for properties like dismutation of radicals and chelate formation [13].

The PP extract showed the highest antioxidant activity, $68.5 \%$ more than GCS and $74.57 \%$ more than KW. The antioxidant activity of the PP extract, presented in Figure 2, is almost equal in all the three extraction conditions. The intense color change from deep purple to yellow observed while adding DPPH to the PP extract means that its proton-releasing ability is very high for free radicals [29]. One of the reasons for the highest antioxidant activity of PP extract was the presence of polyphenols with highly reactive multiple hydroxyl groups $[25,29]$. As far as

Table 2: Change in TPC before and after adsorption of $\mathrm{Cr}(\mathrm{VI})$ from $50 \mathrm{mg} / \mathrm{l}$ solution.

\begin{tabular}{|c|c|c|c|c|c|c|c|c|c|}
\hline \multirow{2}{*}{$\begin{array}{l}\text { Condition for } \\
\text { extraction }\end{array}$} & \multicolumn{3}{|r|}{ PP } & \multicolumn{3}{|r|}{ GCS } & \multicolumn{3}{|r|}{ KW } \\
\hline & $\begin{array}{r}\text { Initial } \\
\text { TPC }\end{array}$ & $\begin{array}{r}\text { Final } \\
\text { TPC }\end{array}$ & $\begin{array}{r}\% \text { Change } \\
\text { in TPC }\end{array}$ & $\begin{array}{r}\text { Initial } \\
\text { TPC }\end{array}$ & $\begin{array}{r}\text { Final } \\
\text { TPC }\end{array}$ & $\begin{array}{r}\% \text { Change } \\
\text { in TPC }\end{array}$ & $\begin{array}{r}\text { Initial } \\
\text { TPC }\end{array}$ & $\begin{array}{r}\text { Final } \\
\text { TPC }\end{array}$ & $\begin{array}{r}\% \text { Change } \\
\text { in TPC }\end{array}$ \\
\hline $12 \mathrm{~h}$ & 134.42 & 17.20 & 87.21 & 15.28 & 0.00 & 100.00 & 7.59 & 0.00 & 100.00 \\
\hline $3 \mathrm{~h}$ & 150.75 & 12.39 & 91.78 & 11.43 & 0.00 & 100.00 & 4.71 & 0.00 & 100.00 \\
\hline $3 \mathrm{~h}$ and $\mathrm{pH} 2$ & 140.18 & 10.47 & 92.53 & 12.39 & 0.00 & 100.00 & 3.75 & 0.00 & 100.00 \\
\hline
\end{tabular}




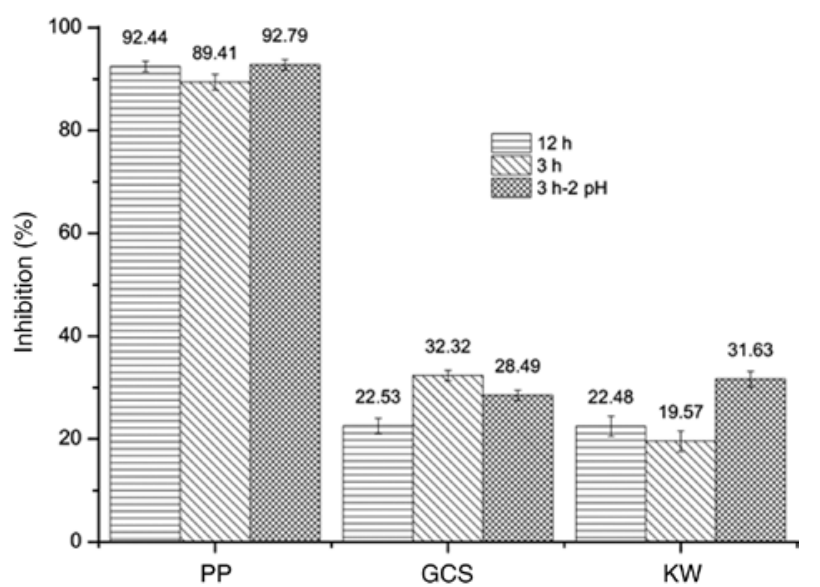

Figure 2: Percentage inhibition or antioxidant activity of extracts at different extraction conditions.

the extracts of GCS and KW are concerned, the antioxidant activity is nearly the same, as the amount of organic compounds released was very low and have been consumed completely.

\subsection{TFC}

Quercetin, a higher electron donor among the investigated flavonoids, was used in the quantification of TFC in the extracts. Moreover, the presence of quercetin has been already reported in the contents of PP extract [13].

Figure 3 shows the quercetin calibration curve for the TFC, and the variation in the level of flavonoids is shown in Figure 4. Figure 4 indicates that the TFC is higher in PP compared to the other two extracts. It is evident that the TFC of the extracts are lesser than the TPC but still present a higher level in PP compared to GCS and KW.

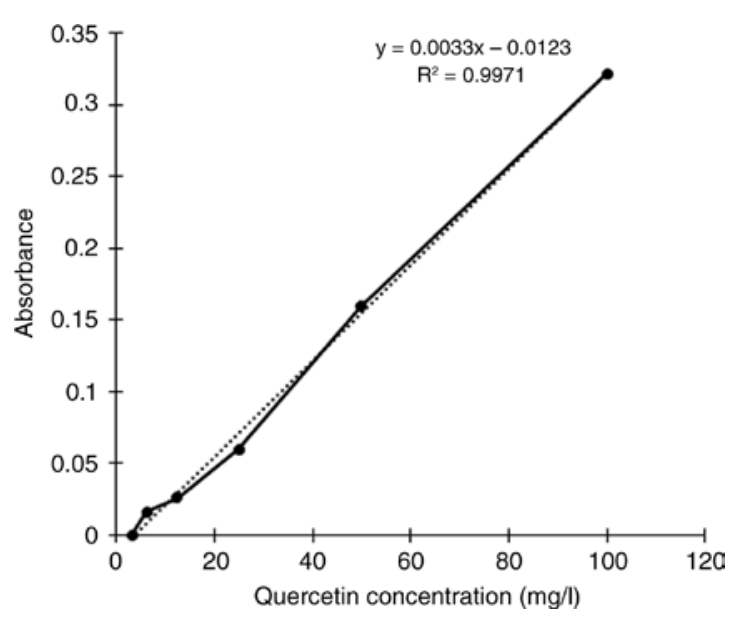

Figure 3: Quercetin calibration curve for flavonoid quantification.

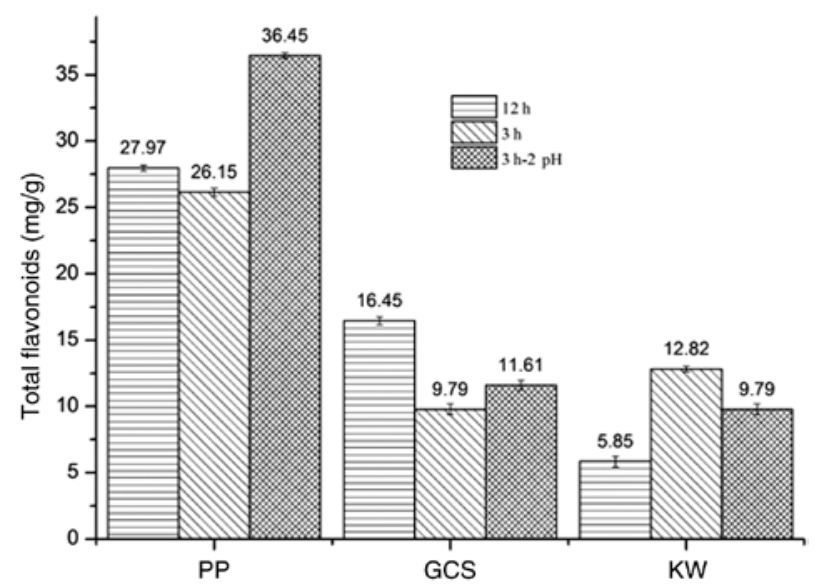

Figure 4: TFC in PP, GCS, and KW extracts for $12 \mathrm{~h}, 3 \mathrm{~h}$, and $3 \mathrm{~h}$ at pH 2 extraction.

\section{5 $\mathrm{Cr}(\mathrm{VI})$ removal}

For all extracts, the maximum removal of $\mathrm{Cr}(\mathrm{VI})$ with $50 \mathrm{mg} / \mathrm{l}$ occurred for the $12 \mathrm{~h}$ extract compared to the removal with the $3 \mathrm{~h}$ and $3 \mathrm{~h}$ at $\mathrm{pH} 2$ extracts. The $\mathrm{Cr}(\mathrm{VI})$ disappearance reached 100\% within $6 \mathrm{~min}$ for the PP extract; however, in the case of the other two, the maximum removal was $<25 \%$ after $3 \mathrm{~h}$. In the case of the GCS extract after $120 \mathrm{~min}$, the removal became almost saturated to about $20 \%$ for the $12 \mathrm{~h}$ extract and to about $10 \%$ for the $3 \mathrm{~h}$ and $3 \mathrm{~h}$ at $\mathrm{pH} 2$ extracts. The removal efficiency with the KW extract started decreasing after 120 min for the $12 \mathrm{~h}$ condition and after $60 \mathrm{~min}$ for the other two conditions. PP maintained its efficiency at $>90 \%$ from the third minute onwards for all the three extracts. GCS acquired equilibrium but KW did not stabilize even after $3 \mathrm{~h}$ due to redox reactions. Figure $5 \mathrm{~A}-\mathrm{C}$ confirm the percentage removal of $\mathrm{Cr}(\mathrm{VI})$ using the PP, GCS, and KW extracts at $303 \mathrm{~K}$ and $\mathrm{pH} 2$ for $50 \mathrm{mg} / \mathrm{l}$ chromium solution.

$\mathrm{Cr}(\mathrm{VI})$ removal studies at 20 and $100 \mathrm{mg} / \mathrm{l}$ concentrations were also performed for the PP extract, which show its high removal efficiency. It was observed that for $20 \mathrm{mg} / \mathrm{l} \mathrm{Cr}$ (VI) solution, $100 \%$ removal was attained at the third minute for all three conditions $(12 \mathrm{~h}, 3 \mathrm{~h}$, and $3 \mathrm{~h}$ at $\mathrm{pH}$ 2). For $100 \mathrm{mg} / \mathrm{l}$, at equilibrium, the removal rate was $99.80 \%, 98.78 \%$, and $96.33 \%$ for $12 \mathrm{~h}, 3 \mathrm{~h}$, and $3 \mathrm{~h}$ at $\mathrm{pH} 2$, respectively. The difference between total chromium (from AAS) and $\mathrm{Cr}(\mathrm{VI})$ reflected the negligible presence of $\mathrm{Cr}(\mathrm{III})$ due to shift reactions in all three extracts.

In Figure 6, showing the FTIR spectra of all extracts, peaks were observed in the area of wavenumber ranging between 1500 and $400 \mathrm{~cm}^{-1}$, representing the presence of carboxylic acids, aromatics, alkyl halides, and amides. The disappearance of all these groups and the increase in 
A

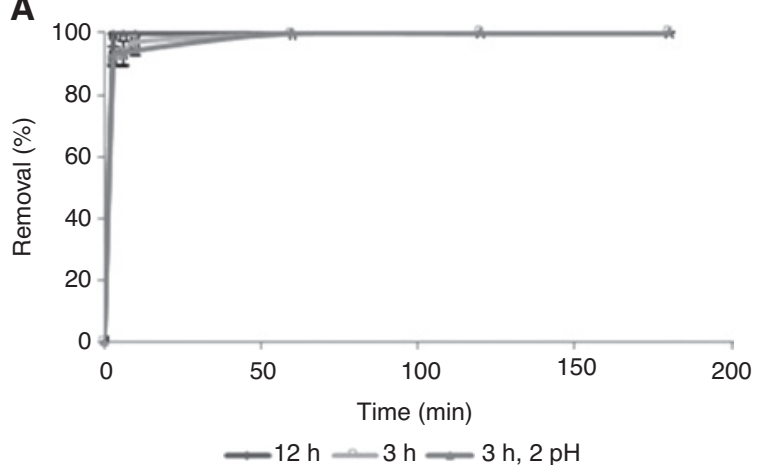

B

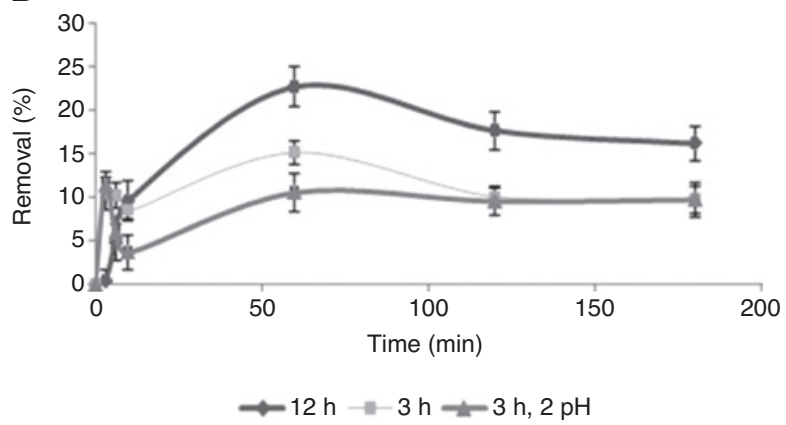

C

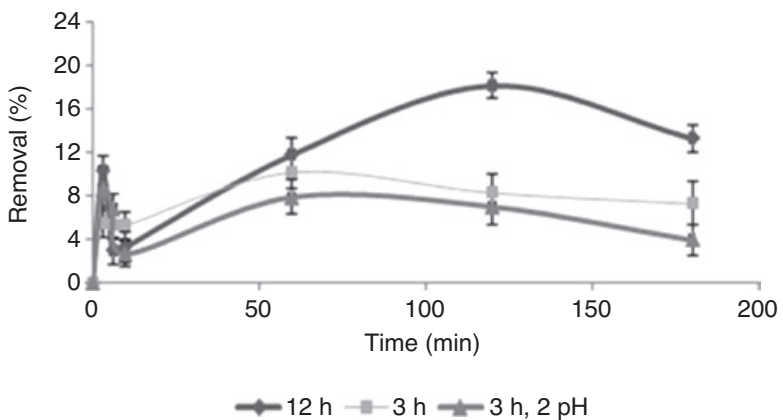

Figure 5: Percentage removal of $\mathrm{Cr}(\mathrm{VI})$ using (A) $\mathrm{PP},(\mathrm{B}) \mathrm{GCS}$, and (C) $\mathrm{KW}$ extracts at $303 \mathrm{~K}$ and $\mathrm{pH} 2$.

the intensity of peaks at wavenumbers 1629 and $3306 \mathrm{~cm}^{-1}$ showed the major role of these compounds in the removal of $\mathrm{Cr}(\mathrm{VI})$. Also, these results with the three extracts, in general, gave a clear depiction of the role of functional groups deriving the possible reaction mechanisms.

$\mathrm{Cr}(\mathrm{VI})$ on hydrolysis gives $\mathrm{CrO}_{4}{ }_{4}^{2-}, \mathrm{HCrO}_{4}^{-}$, and $\mathrm{Cr}_{2} \mathrm{O}_{7}{ }^{2-}$ $[3,10]$. The chromate anions react with the organic matter present in the peel extracts to produce $\mathrm{Cr}$ (III) as per the following reduction mechanism:

$$
\mathrm{HCrO}_{4}^{-}+\text {organic matter }+\mathrm{H}^{+} \rightarrow \mathrm{Cr}^{3+}+\mathrm{H}_{2} \mathrm{O} .
$$

Moreover, on further oxidation,

$$
\mathrm{HCrO}_{4}^{-}+\text {organic matter }+\mathrm{H}^{+} \rightarrow \mathrm{CrO}_{4}^{2-}+\mathrm{CO}_{2} \text {. }
$$

A

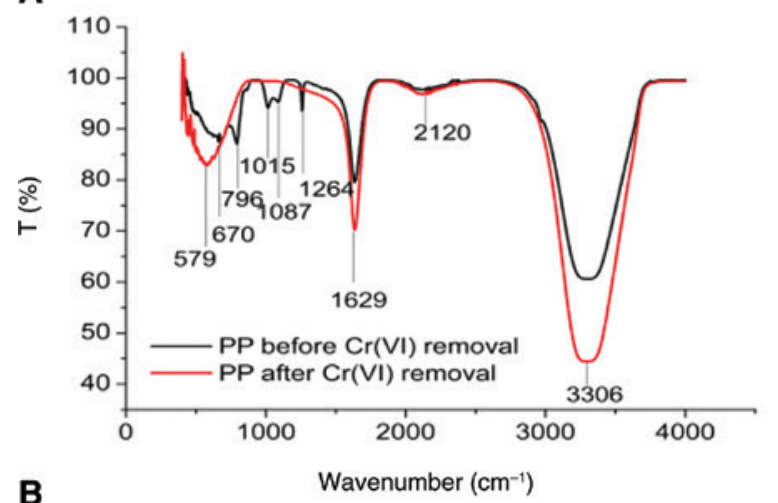

B
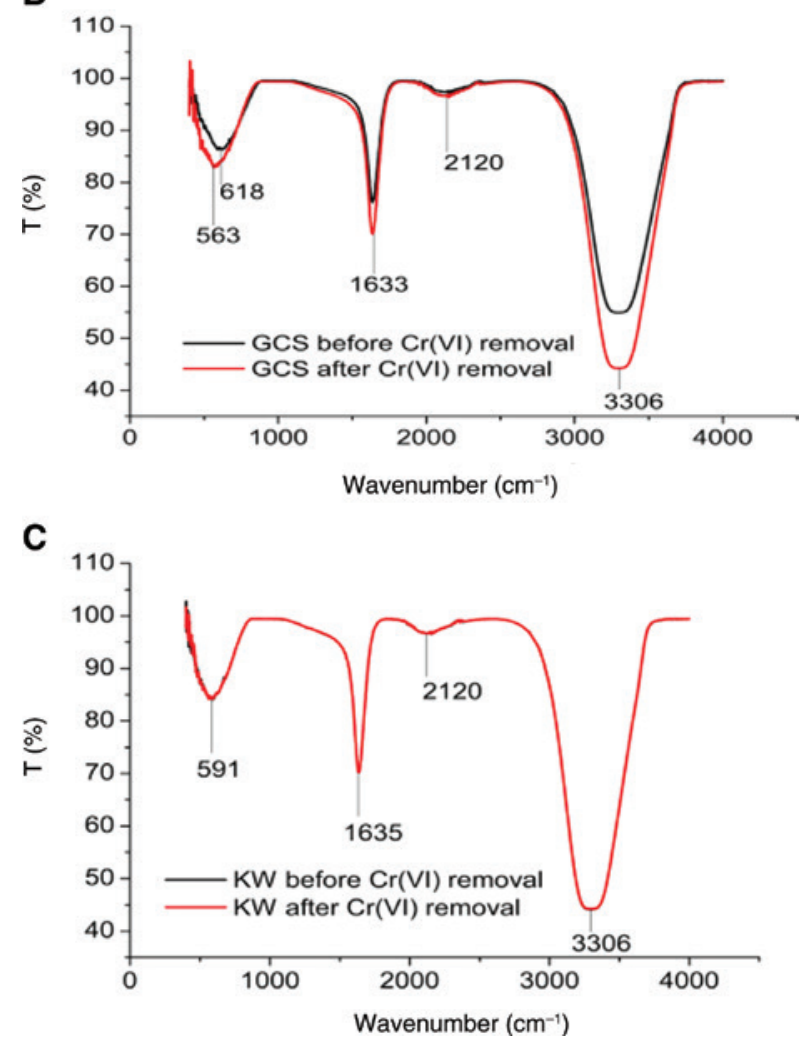

Figure 6: FTIR spectrum of (A) PP, (B) GCS, and (C) KW before and after treatment with $\mathrm{Cr}(\mathrm{VI})$ at $303 \mathrm{~K}$ and $\mathrm{pH} 2$.

The expected mechanisms due to the presence of phenolic and carboxylic groups are as follows:

$$
\begin{gathered}
\cdots \mathrm{COOH}+\mathrm{M}^{n+} \rightarrow \cdots \mathrm{COOM}^{(n-1)+}+\mathrm{H}^{+}, \\
\cdots \mathrm{C}_{6} \mathrm{H}_{5} \cdots \mathrm{OH}+\mathrm{M}^{n+} \rightarrow \cdots \mathrm{C}_{6} \mathrm{H}_{5} \cdots \mathrm{OM}^{(n-1)+}+\mathrm{H}^{+}, \\
\cdots \mathrm{COOH}+\mathrm{M}(\mathrm{OH})^{(n-1)+} \rightarrow \cdots \mathrm{COOM}(\mathrm{OH})^{(n-2)+}+\mathrm{H}^{+} \\
\cdots \mathrm{C}_{6} \mathrm{H}_{5}-\mathrm{OH}+\mathrm{M}(\mathrm{OH})^{(n-1)+} \rightarrow \cdots \mathrm{C}_{6} \mathrm{H}_{5} \cdots \mathrm{OM}(\mathrm{OH})^{(n-2)+}+\mathrm{H}^{+},(9)
\end{gathered}
$$

where $M$ is the metal ion. 
From the experimentation, it was confirmed that the higher the antioxidant activity, phenolic content, and flavonoid content, the better is the removal of $\mathrm{Cr}(\mathrm{VI})$. Metal chelation reaction occurred due to the presence of a high amount of polyphenolic compounds. Phenolic compounds with three hydroxyl radicals release protons easily to form metal chelates. This chelation should have been the reason for not showing the peak at $540 \mathrm{~nm}$ in the ultraviolet spectrophotometer. The experimental results also complemented the reaction mechanism that the pigments released during biosorption have a major role in the removal of $\mathrm{Cr}(\mathrm{VI})$.

\section{Conclusion}

Organic compounds released during the biosorption of $\mathrm{Cr}(\mathrm{VI})$ using PP, GCS, and KW extracts were quantified using COD analysis. After treatment with $50 \mathrm{mg} / \mathrm{l} \mathrm{Cr}(\mathrm{VI})$ solution, these extracts showed a heavy reduction of COD in PP compared to KW and GCS. TPC, antioxidant activity, and TFC were observed to be in the order of PP $>$ GCS $>$ KW, crediting the PP extract for better removal of the metal ion. A $100 \%$ removal of $\mathrm{Cr}(\mathrm{VI})$ solution with 20 and $50 \mathrm{mg} / \mathrm{l}$ and a $>96 \%$ removal with $100 \mathrm{mg} / \mathrm{l}$ were attained with the PP extract. Metal chelation reaction occurred during the interaction between extract and chromium solution, which might be the reason for the non-detection of metal ion present in the medium. The higher efficiency of the PP extract establishes that it is a good, sustainable, ecofriendly solution for the removal of $\mathrm{Cr}(\mathrm{VI})$ from aqueous medium compared to GCS and KW.

Acknowledgments: The authors thank the director of NIT, Tiruchirappalli; Dr. S. Velmathi, Department of Chemistry, NIT, Tiruchirappalli; and head of Chemical Engineering Department and research scholars of the Chemical Engineering Department, NIT, Tiruchirappalli, especially Navamani Kartic D, Tamilmani J, Indulekha John, Bhuvaneswari $\mathrm{G}$, and Selvakumar P for extending all facilities and support in completing this work.

\section{References}

[1] Khitous M, Salem Z, Halliche D. Chinese J. Chem. Eng. 2016, 24, 433-445.
[2] Kumar S, Meikap BC. Desalin Water Treat. 2013, 52, 3122-3132.

[3] Mohan D, Singh KP, Singh VK. Ind. Eng. Chem. Res. 2005, 44, 1027-1042.

[4] Mohan D, Pittman CU. J. Hazard Materm. 2006, 137, 762-811.

[5] Indian Standards Institute. IS 10500 2013, 10.

[6] Kowalski KP. Chemistry of Advanced Environmental Purification Processes of Water. Elsevier: Denmark, 2014.

[7] Indian Standards IS 10500 2012, Drinking water. p 1-3.

[8] Gordon B, Callan P, Vickers C. WHO guidelines for drinkingwater quality, WHO Chron. 2008, 38, 564.

[9] Elangovan R, Philip L, Chandraraj K. Chem. Eng. J. 2008, 141, 99-111.

[10] Elangovan R, Philip L, Chandraraj K. J. Hazard Mater. 2008, 152, 100-112.

[11] Shyamala Gowri S, Pavitha S, Vasantha K. Int. J. Pharm. Pharm. Sci. 2011, 3, 160-164.

[12] Abdel-Ghani N, El-Chaghaby G. MNKJ. Com. 2014, 3, 24-42.

[13] Viuda-Martos M, Fernandez-Lopez J, Perez-Alvarez JA. Compr. Rev. Food Sci. Food Saf. 2010, 9, 635-654.

[14] Bansal M, Garg U, Singh D, Garg VK. J. Hazard Mater. 2009, 162, 312-320.

[15] Vargas-Morales JM, Bautista-Mata D, Cárdenas-González JF, Martínez-Juárez VM, Acosta-Rodríguez I. Online 2012, 2012, 19-24.

[16] Huang K, Xiu Y, Zhu H. Int. J. Environ. Sci. Technol. 2015, 12, 2485-2492.

[17] American Public Health Association. Standard Methods for the Examination of Water and Wastewater, 18th ed., American Public Health Association: Washington DC, 1992.

[18] Madaan R, Kumar S, Bansal G, Sharma A. Indian J. Pharm. Sci. 2011, 73, 666.

[19] Shah RK, Yadav RNS. Global J. Bio-Sci. Biotechnol. 2015, 4, 81-84.

[20] Aksoy L, Kolay E, Aĝilönü Y, Aslan Z, Kargioĝlu M. Saudi J. Biol. Sci. 2013, 20, 235-239.

[21] Kalita P, Barman TK, Pal TK, Kalita R. J. Drug Deliv. Ther. 2013, 3, 33-37.

[22] Sahu R, Saxena J. Int. J. Pharm. Sci. Rev. Res. 2013, 21, 24-26.

[23] Al-rawahi AS, Edwards G, Al-sibani M, Al-thani G, Al-harrasi AS, Rahman MS. Eur. J. Med. Plants 2014, 4, 315-33.

[24] Balasundram N, Sundram K, Samman S. Food Chem. 2006, 99 , 191-203.

[25] Rodrigues S, Pinto GAS. J. Food Eng. 2007, 80, 869-872.

[26] Dave PN, Bhandari J. Int. J. Chem. Stud. 2013, 1, 181-196.

[27] Mathew S, Abraham TE, Zakaria ZA. J. Food Sci. Technol. 2015, 52, 5790-5798.

[28] Shahidi F, Janitha PK, Wanasundara PD. Crit. Rev. Food Sci. Nutr. 1992, 32, 67-103.

[29] Aloqbi A, Omar U, Yousr M, Grace M, Lila A. Nat. Sci. 2016, 8, 235-246. 